\title{
Landslides into reservoirs and their impacts on banks
}

\author{
Rita Fernandes de Carvalho . \\ José Simão Antunes do Carmo
}

Received: 16 July 2007 / Accepted: 6 September 2007 / Published online: 5 October 2007

(C) Springer Science+Business Media B.V. 2007

\begin{abstract}
Mass wasting processes, like slope failures, on the margins of dam reservoirs, lakes, bays and oceans may generate large water waves that can produce disasters due to flooding over the banks, run up along the shoreline and overtopping dam crests. Therefore, the study of slope failures, the subsequent generation of impulse waves and their consequences are of paramount importance for safety. In this paper the generation and propagation of water waves in reservoirs induced by landslides and their impact on banks were investigated by means of a laboratory study carried out at University of Coimbra wave channel, in a flume measuring $12.0 \mathrm{~m} \times 1.5 \mathrm{~m} \times 1.0 \mathrm{~m}(\mathrm{~L} \times \mathrm{H} \times \mathrm{W})$, where two banks with variable slope were placed. The study considered the sliding of calcareous blocks over a sliding slope bank into the reservoir, the generation of impulse waves, their propagation in the reservoir and their impact on the downstream bank. A number of waves were generated by different fallings of calcareous blocks, considering different volumes, sliding slopes, initial positions and reservoir depths. All fallings were recorded by video-camera and the results were processed afterwards to obtain the time history of the falling. The water surface variations due to transient waves were measured at five gauges placed between the banks. The waves overtopping and breaking on the downstream bank were also filmed using a video camera, and the hydrodynamic forces on this bank were also measured using four pressure transducers.
\end{abstract}

Keywords Reservoir - Landslides · Waves · Pressure diagrams · Hydrodynamic forces · Laboratory experiments

R. F. de Carvalho $(\varangle) \cdot$ J. S. Antunes do Carmo

IMAR, Civil Engineering Department, University of Coimbra, Rua Luís Reis Santos Pólo II

da Universidade de Coimbra, Pinhal de Marrocos, 3030-788 Coimbra, Portugal

e-mail: ritalmfc@dec.uc.pt

J. S. Antunes do Carmo

e-mail: jsacarmo@dec.uc.pt 

Abbreviations
FCT
Portuguese Foundation for Science and Technology
LHRHA-DEC-FCTUC
Laboratório de Hidráulica, Recursos Hídricos e Ambiente,
Departamento de Engenharia Civil, Faculdade de Ciências
e Tecnologia da Universidade de Coimbra

Notations
$F=v_{s} / \sqrt{g h_{0}}$
$v_{s}$
$h_{0}$
$g$
$V=V_{s} /\left(b h_{0}^{2}\right)$
$V_{\mathrm{s}}$
$b$
$S=s / h_{0}$
$s$
$\rho_{s}$
$\eta_{\text {por }}$
$\alpha$
$\phi$
$M$
$M_{w}$
$\rho_{w}$
$C_{x}$
$A$
$t$
$\Delta z$
$a_{c}$
$L$
$c_{c 1}$

Froude number for sliding velocity

Sliding velocity

Initial reservoir water level

Acceleration due to gravity

Dimensionless slide volume

Slide volume

Slide width

Dimensionless slide thickness

Slide thickness

Density of slide mass/slide mass material density

Porosity (slide mass material)

Bank slope

Friction slope

Mass of the sliding blocks

Submerged mass

Water density

Drag coefficient for the slide

Slide mass section

Time of the sliding

Vertical distance between initial and final positions

of the mass centre

Positive wave amplitude

Wave length

Wave propagation velocity/celerity

\section{Introduction}

The relevant area prone to flooding and mass wasting processes are due to both natural and anthropogenic causes, which include: poor quality of construction and construction materials; improper reservoir management, and also acts of war. Factors that generate the first movement include high gradient, slope saturation by ground water and undermining, and the most frequent are induced by heavy rains and earthquakes.

These processes, namely laminar erosion, slides, landslides and lateral undermining vary with various factors that combine to create instability. Some are active, stabilized or tend to be reactivated especially when the site cover is changed by vegetation, water or urban construction, or if they are placed in a seismic activity zone. Additionally, reservoir dams are often placed in active earthquakes areas and large new reservoirs can trigger seismic activity, immediately after filling or after a delay depending on the permeability.

Several ways of landslides classification could be used: sliding mass can be initially non submerged, partially or completely submerged; the material can be more or less compact or dense, granular or fine (rock and soil, snow); the sliding mass volume could be variable from 
small to great volumes; sliding mass velocity at the moment of impact is dependent on the balance forces/moments, which are influenced by the dynamic properties of soil, by the soil brittleness and by topographic effects; the size or volume, and the reservoir depth.

A bank-reservoir system exposed to transitory phenomena like earthquakes or impulse waves behaves like non linear mechanisms. The reservoir bottom is an important factor in the propagation and may affect the magnitude of the hydrodynamic forces on the bank. In the majority of cases the concrete or rock banks remain elastic and transient analysis of structures interacting with fluid is necessary for realistic analysis. The banks made of other materials could become unsafetely.

The study of these phenomena, including slope failures, the generation and propagation of waves and their impact on dams or other banks should be integrated. This work was prepared in the scope of a research project entitled "Dam breaks: the study of natural and technological causes and the modelling of associated hydrodynamic, geo-technical and sedimentary problems", funded by the FCT - the Portuguese Foundation for Science and Technology — under the POCTI/ECM/2688/2003 project.

Experimental studies of impulse waves generated by landslides composed by granular rockslide can be found in Fritz [2] and Fritz et al. [3]. Fritz [2] investigated the initial phase of landslide generated impulse wave by means of a large scale digital particle image velocimetry and laser distance sensors, and considered four relevant parameters governing the wave generation: granular slide mass, slide impact velocity, stillwater depth and slide thickness. Fritz et al. [3] proposed several empirical formulas to predict the wave characteristics, based on three fundamental dimensionless parameters: slide Froude number, $F=v_{s} / \sqrt{g h_{0}}$, where $v_{s}$ is the slide velocity, $h_{0}$ is the initial reservoir water level and $g$ the acceleration due to gravity; dimensionless slide volume, $V=V_{s} /\left(b h_{0}^{2}\right)$, where $V_{s}$ is the slide volume and $b$ is the slide width, and dimensionless slide thickness, $S=s / h_{0}$, where $s$ is the slide thickness.

A large set of numerical experiments were carried out by Lynett and Liu [4] in order to examine maximum run-up at a beach, generated by submerged and subaerial solid body landslides. The simulations were based in varying one of the six dimensionless parameters: the slide thickness, the slide wave number, a slide shape, the horizontal aspect ratio of the slide, the specific gravity of the slide mass and the beach slope. They found some interesting results, which could be useful for preliminary hazard assessment, particularly for the maximum run-up and locations. Carvalho and Antunes do Carmo [1] also investigated the generation of waves processing the images by video camera recordings and including these data as boundary conditions of two different numerical models. They presented results that show an acceptable agreement with experimental data.

In this work, the waves generated by calcareous blocks sliding over inclined planes were studied. Several parameters were tested: two values for the sliding mass volume, two values of gate position, for avoiding two different high falls; two values for the bank variable bank slope and four values for the variable water depth. The laboratory study of the wave characteristics and the hydrodynamic effects caused by landslides was based on a test matrix that included 20 different conditions. For each test, sketches were made in order to characterize the landslide initial and final positions, including mass centre calculation, and relate them with the waves generated. Three kinds of measurements were done: slide velocity during the fall by video recordings and laser equipment fixed on the channel wall; water level variations in the reservoir by five gauges, and hydrodynamic forces on the second bank by pressure transducers placed at the downstream bank face.

Different velocity diagrams of landslides and different types of waves were produced. Relevant parameters governing the wave generation were identified. Pressures diagrams and 
Table 1 Mass centre positions for different experiments

\begin{tabular}{lllll}
\hline Name & $\begin{array}{l}\text { Gate position } \\
(\mathrm{cm})\end{array}$ & $\begin{array}{l}\text { Slide slope } \\
\left({ }^{\circ}\right)\end{array}$ & $\begin{array}{l}\text { Volume } \\
\left(\mathrm{m}^{3}\right)\end{array}$ & $\begin{array}{l}\text { Height of centre } \\
\text { of gravity }(\mathrm{cm})\end{array}$ \\
\hline E01, E04, E16, E19, E20 & 51.5 & 30.7 & 0.0814 & 74.15 \\
E02, E05, E15 & 61.5 & 30.7 & 0.0814 & 84.16 \\
E03, E06, E13, E14 & 51.5 & 30.7 & 0.1687 & 85.08 \\
E07, E10, E17 & 51.5 & 39.5 & 0.0814 & 76.60 \\
E08, E11, E18 & 61.5 & 39.5 & 0.0814 & 86.60 \\
E09, E12 & 51.5 & 39.5 & 0.1687 & 89.97 \\
\hline
\end{tabular}

hydrodynamic forces on the upstream face of the downstream bank as well as spectral analyses were also performed.

\section{Laboratory installation and equipment}

The channel of the laboratory installation is $40.0 \mathrm{~m} \times 1.5 \mathrm{~m} \times 1.0 \mathrm{~m}(\mathrm{~L} \times \mathrm{H} \times \mathrm{W})$; the variable sloping bank and the dam were placed along a length of approximately $12 \mathrm{~m}$. The landslide was reproduced in the laboratory installation by calcareous masses that fell by sliding over the bank. Figure 1 shows a view of the laboratory installation.

Sliding masses were simulated by several calcareous blocks, measuring $10 \mathrm{~cm} \times 8 \mathrm{~cm} \times$ $7 \mathrm{~cm}(\mathrm{~L} \times \mathrm{H} \times \mathrm{W})$, and with density $\rho_{s} / \rho=2.38$ and porosity $\eta_{\text {por }} \approx 0.40$. Some blocks were cut to accommodate the gate placed to retain the calcareous material before the experiment. The friction angle was determined experimentally by varying the bank slope with the two different volumes placed above it and without any retention. For the two volumes, $0.0814 \mathrm{~m}^{3}$ and $0.168 \mathrm{~m}^{3}$, friction slope of $\phi \approx 23.83^{\circ}$ and $\phi \approx 26.02^{\circ}$ were obtained with correlation greater than 0.99 . For both volumes of $0.0814 \mathrm{~m}^{3}$ and $0.1687 \mathrm{~m}^{3}$, corresponding to masses of $193.29 \mathrm{Kg}$ and $400.85 \mathrm{Kg}$, respectively, mass centre positions were calculated for the two slopes of the sliding bank $\left(30.7^{\circ}\right.$ and $\left.39.5^{\circ}\right)$ and gate positions $(51.5$ and $61.5 \mathrm{~cm})$. The reservoir water level varied between 0.30 and $0.55 \mathrm{~m}$. Table 1 illustrates the different parameters tested and Fig. 2 illustrates the mass centre positions for both volumes and the sketch for the tests E01, similar to E04, E16, E19 and E20 (different reservoir initial water level), mass $\mathrm{n}^{\circ} 1$, gate $\mathrm{n}^{\circ} 1$ and bank angle $\mathrm{n}^{\circ} 1$; E02 similar to E05 and E15, mass $\mathrm{n}^{\circ} 1$, gate $\mathrm{n}^{\circ} 2$ and bank angle $\mathrm{n}^{\circ} 1$, and E03, similar to E06, E13 and E14, mass $n^{\circ} 2$, gate $n^{\circ} 1$ and bank angle $n^{\circ} 1$.

Fig. 1 General view of the LHRHA-DEC-FCTUC channel with bank slope and dam inside

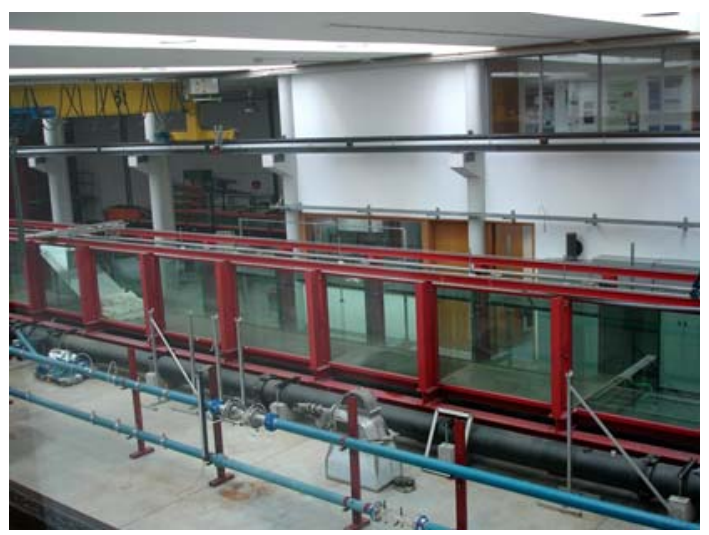




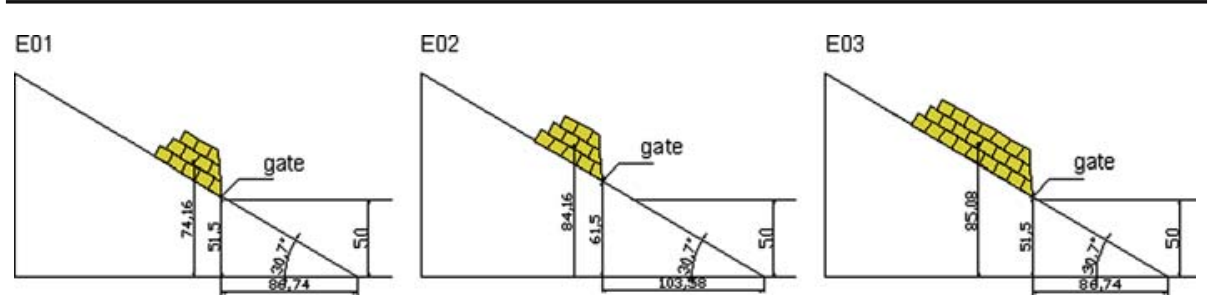

Fig. 2 Calculation of the mass centre position: initial position for the tests: E01, E02 and E03

The bank was made of acrylic glass measuring $2.51 \mathrm{~m} \times 0.992 \mathrm{~m} \times 0.010 \mathrm{~m}(\mathrm{~L} \times \mathrm{W} \times \mathrm{T})$, supported by a metallic structure which allowed the angle slope to vary between $30^{\circ}$ and $45^{\circ}$. On the bank, the gate was placed at positions 0.95 and $1.05 \mathrm{~m}$ away from the bottom. The gate was also made of acrylic glass measuring $0.51 \mathrm{~m} \times 0.98 \mathrm{~m} \times 0.010 \mathrm{~m}(\mathrm{~L} \times \mathrm{W} \times \mathrm{T})$, and moved in two U gutters, connected in a guide pulley system to a counter balance. The falling of the counter balance caused the gate to rise, and so the material to slide. Figure 3 shows the mechanism that allows the material to slide over the bank and the calcareous mass retained by the gate. The movement of the sliding, from the initial position to its final position, was filmed using a video-camera. The images were subsequently analyzed to obtain an estimate of the submerged mass and volume as a function of time, that is $M=f(t)$. This knowledge was required to solve Eq. 1, which describes the movement of the sliding mass:

$$
M \frac{\mathrm{d} v_{s}}{\mathrm{~d} t}=M g \sin \alpha-M_{w} g \frac{\rho_{s}}{\rho_{w}} \sin \alpha-M g \cos \alpha \tan \phi-\frac{1}{2} C_{x} \rho_{w} A v_{s}^{2}
$$

where $M$ is the total sliding mass, $M_{w}$ is the submerged mass, $v_{s}$ is the slide mass velocity, $\alpha$ is the bank slope, $\phi$ is the friction slope, $\rho_{s}$ is the density of slide mass, $\rho_{w}$ is the water density, $C_{x}$ is the drag coefficient for the slide, $A$ is the sliding mass section, $t$ is the time and $g$ is the acceleration due to gravity. Equation 1 was solved with a 4th Runge-Kutta. A laser equipment fixed on the channel wall was also tested, but the channel's glass characteristics meant that the measurements were not reliable.

The time history of the water level and pressure on the upper face of the second bank were also measured simultaneously using software that allows real time visualization on the computer. The downstream bank was also made of acrylic glass $0.78 m \times 0.992 m \times 0.010 m$ $(\mathrm{L} \times \mathrm{W} \times \mathrm{T})$, and with an upstream face angle of $40^{\circ}$. Between the sliding bank and the second bank, five probes with an accuracy of $1 \mathrm{~mm}$ and an acquisition of $20 \mathrm{~Hz}$ (HR Wallingford wave probe monitors $0.6 \mathrm{~m}$ ) were positioned at 2, 4, 6 and $8 \mathrm{~m}$ away from the bank for measuring the water level variation. A probe closer to the mass slide impact was desirable, but this position could not be secure for the probe. The wave impact and reflection on the upper face of the second bank were also obtained in the laboratory experiments. This was done by measuring both the wave height and the pressure exerted on the wall. Figure 4 shows a gauge and the four pressure transducers placed on the downstream bank face.

\section{Experimental tests results}

Figure 5 shows a sketch of the laboratory installation, including the reservoir, the two banks: the sliding slope and the downstream bank; the water mass in the reservoir, the gate, the gauges between the two banks and the pressure transducers at the second bank face. The laboratory study of the wave characteristics and the hydrodynamic effects caused by landslides was 
Fig. 3 View of different calcareous blocks, mechanism that allows the material to slide over the bank and the calcareous mass retained by the gate
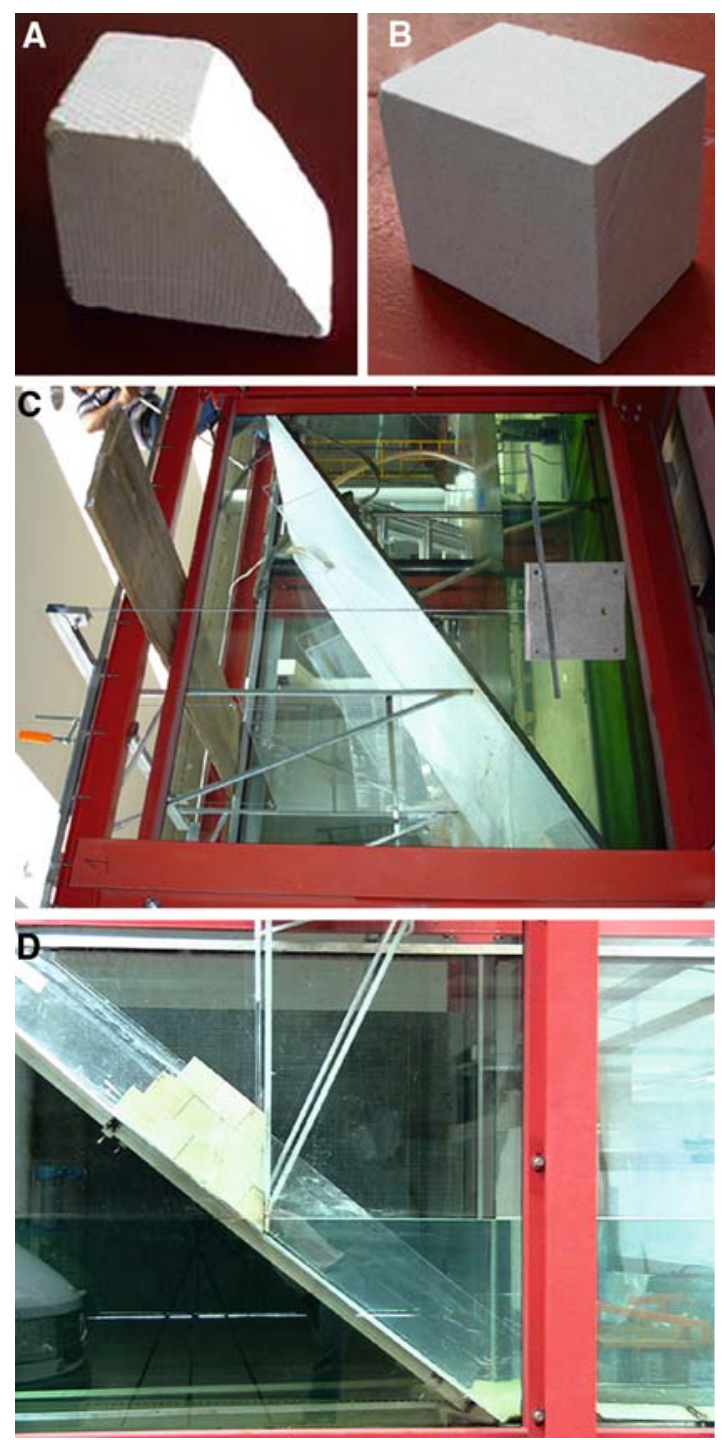

based on a test matrix that included 20 different conditions. Table 2 shows the different parameter values chosen for the experiments.

For all experiments, the images were processed by video recordings and the positions of the sliding blocks were calculated using Eq. 1. Different velocity diagrams of landslide fall were produced: parabolic (E01-E12, E19 and E20), quasi-linear (E13-E17) and quasisinusoidal (E18). Figure 6 shows the variation of the sliding mass velocity during the fall calculated by Eq. 1 for the essays E01-E08, E10-E12 and E16-E18. Analysing Fig. 6 and Table 2, it can be concluded that sudden descending variations occurred due to the reservoir water level, which is not deep enough to decelerate the sliding mass. In general, a higher initial position of the centre of gravity corresponds to a higher initial velocity, and a higher slope corresponds to a more pronounced increase in slide velocity. This slide slope has a great 

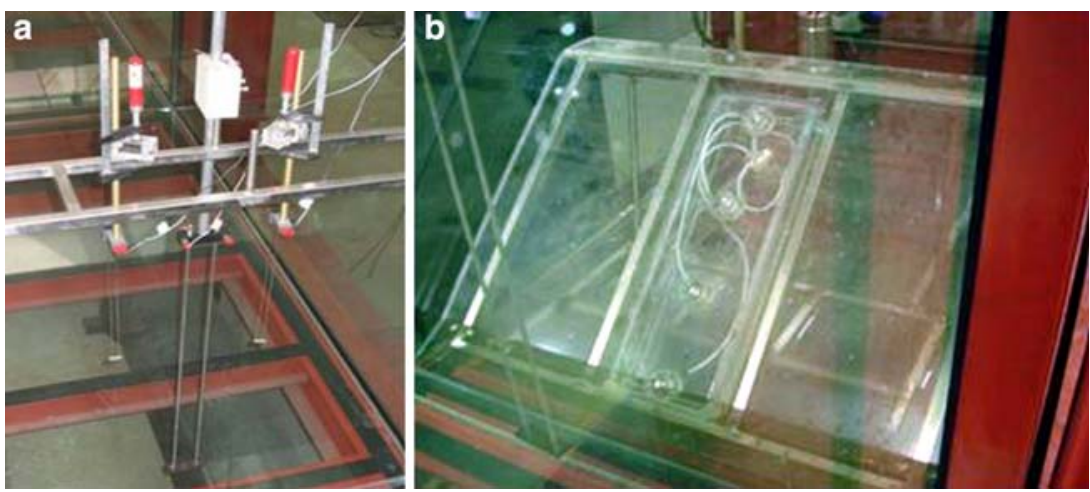

Fig. 4 A gauge for water level measurements and the pressure transducers placed on bank downstream upper face

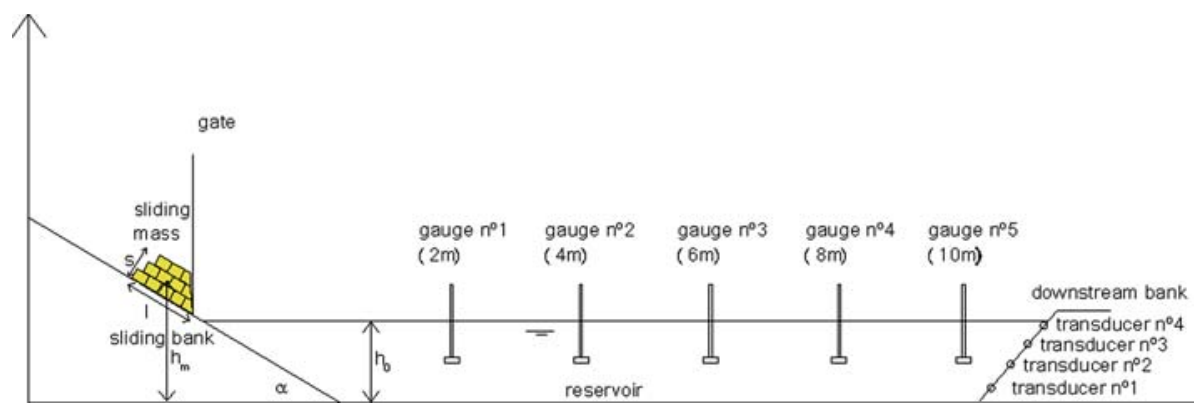

Fig. 5 Definition sketch of the experiments

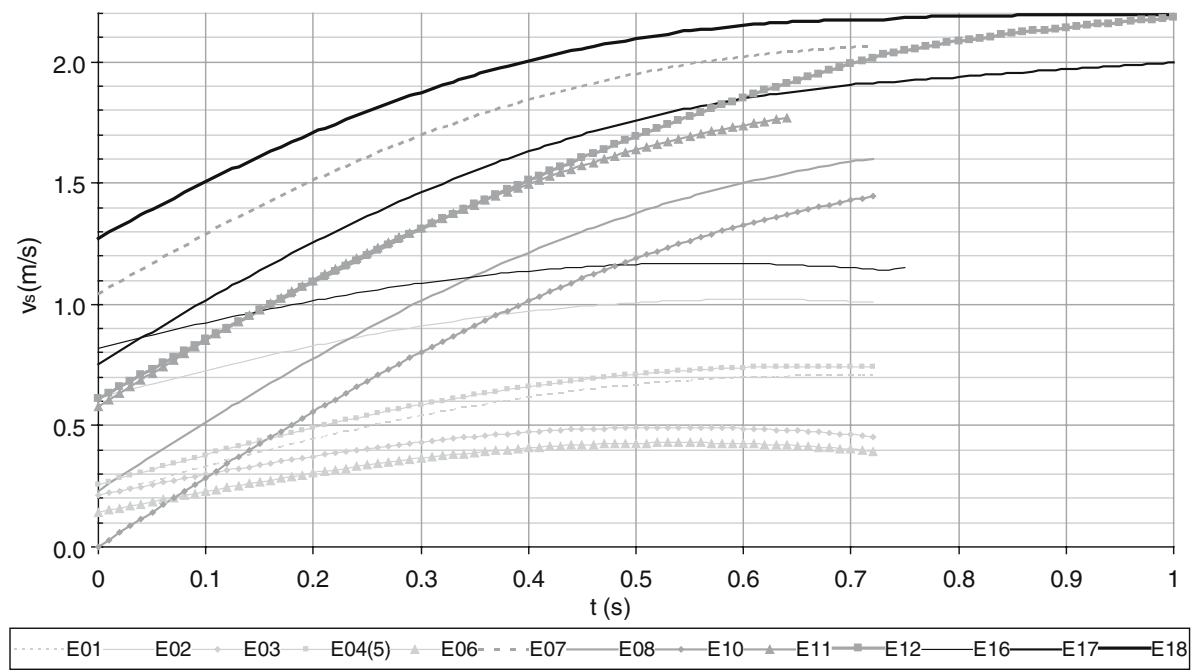

Fig. 6 Slide mass velocity diagrams during sliding: Tests E01-08, E10-12; E16-18 
Table 2 Parameter values for different experiments

\begin{tabular}{lllll}
\hline Name & $\begin{array}{l}\text { Slide slope } \\
\left({ }^{\circ}\right)\end{array}$ & $\begin{array}{l}\text { Reservoir } \\
\text { water level } \\
(\mathrm{m})\end{array}$ & $\begin{array}{l}\text { Slide } \\
\text { volume }\left(\mathrm{m}^{3}\right)\end{array}$ & $\begin{array}{l}\text { Centre of } \\
\text { gravity }(\mathrm{m})\end{array}$ \\
\hline E01 & 30.7 & 0.5 & 0.0814 & 0.74 \\
E02 & 30.7 & 0.5 & 0.0814 & 0.84 \\
E03 & 30.7 & 0.5 & 0.1687 & 0.85 \\
E04 & 30.7 & 0.55 & 0.0814 & 0.74 \\
E05 & 30.7 & 0.55 & 0.0814 & 0.84 \\
E06 & 30.7 & 0.55 & 0.1687 & 0.85 \\
E07 & 39.5 & 0.5 & 0.0814 & 0.77 \\
E08 & 39.5 & 0.5 & 0.0814 & 0.87 \\
E09 & 39.5 & 0.5 & 0.1687 & 0.90 \\
E10 & 39.5 & 0.55 & 0.0814 & 0.77 \\
E11 & 39.5 & 0.55 & 0.0814 & 0.87 \\
E12 & 39.5 & 0.55 & 0.1687 & 0.90 \\
E13 & 30.7 & 0.5 & 0.1687 & 0.85 \\
E14 & 30.7 & 0.4 & 0.1687 & 0.85 \\
E15 & 30.7 & 0.3 & 0.0814 & 0.84 \\
E16 & 30.7 & 0.3 & 0.0814 & 0.74 \\
E17 & 39.5 & 0.3 & 0.0814 & 0.77 \\
E18 & 39.5 & 0.3 & 0.0814 & 0.87 \\
E19 & 30.7 & 0.4 & 0.0814 & 0.74 \\
E20 & 30.7 & 0.45 & 0.0814 & 0.74 \\
\hline
\end{tabular}

influence on the maximum slide mass velocity (see E01 and E07). For the larger angle, the maximum velocity difference becomes visible (E08 and E11). Similar results were observed for the slide mass volume (E01 and E03). However, the slide mass volume variation could not be analyzed separated from the initial position of the mass centre. This parameter is very important both the initial and maximum slide mass velocity (see E01 and E02, E07 and E08, $\mathrm{E} 10$ and E11, or E16 and E17). In particular, when the initial water level is low, this parameter causes large slide initial velocity (see E16 and E17). The initial water level position is less important for small bank angles (slide mass velocity variation during the fall is similar in E01-E03). The maximum slide velocity was also determined by the following expression deduced from the energy balance between the initial and final positions of the slide:

$$
v_{s m}=\sqrt{2 g \Delta z \sin (\alpha-\phi)}
$$

where $v_{s m}$ is the slide velocity when the mass centre reaches the water surface, $\Delta z$ is the height of the positions of the mass centre before and after the mass sliding, $g$ is the acceleration due to gravity, $\alpha$ is the slide slope and $\phi$ is the friction slope. In the majority of the tests, an acceptable agreement with the maximum slide velocity calculated by Eqs. 1 and 2 was observed, except for the lower slide slopes and smaller heights of the centre of gravity. Those differences do not interfere with the prediction of wave type based on the Froude number for sliding velocity and dimensionless slide thickness proposed by Noda [5]: nonlinear for $F=v_{s} / \sqrt{g h_{0}}<4-7.5 S$; oscillatory for $4-7.5 S<F<6.6-8 S$; solitary for $6.6-8 S<F<8.2-8 S$ and dissipative for $F>8.2-8 S$. However, when it comes to inflow boundary condition in numerical simulations, these differences are very important [1]. The relevant parameters governing slide velocity, and so wave generation, consist of: the mass of the sliding blocks, 

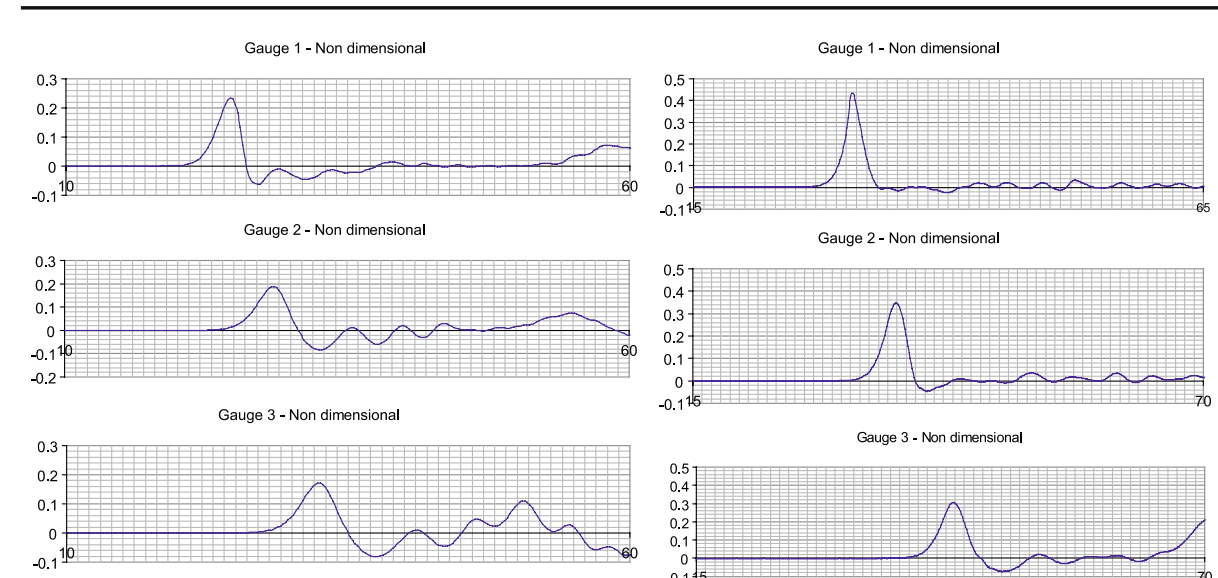

Gauge 4 - Non dimensional
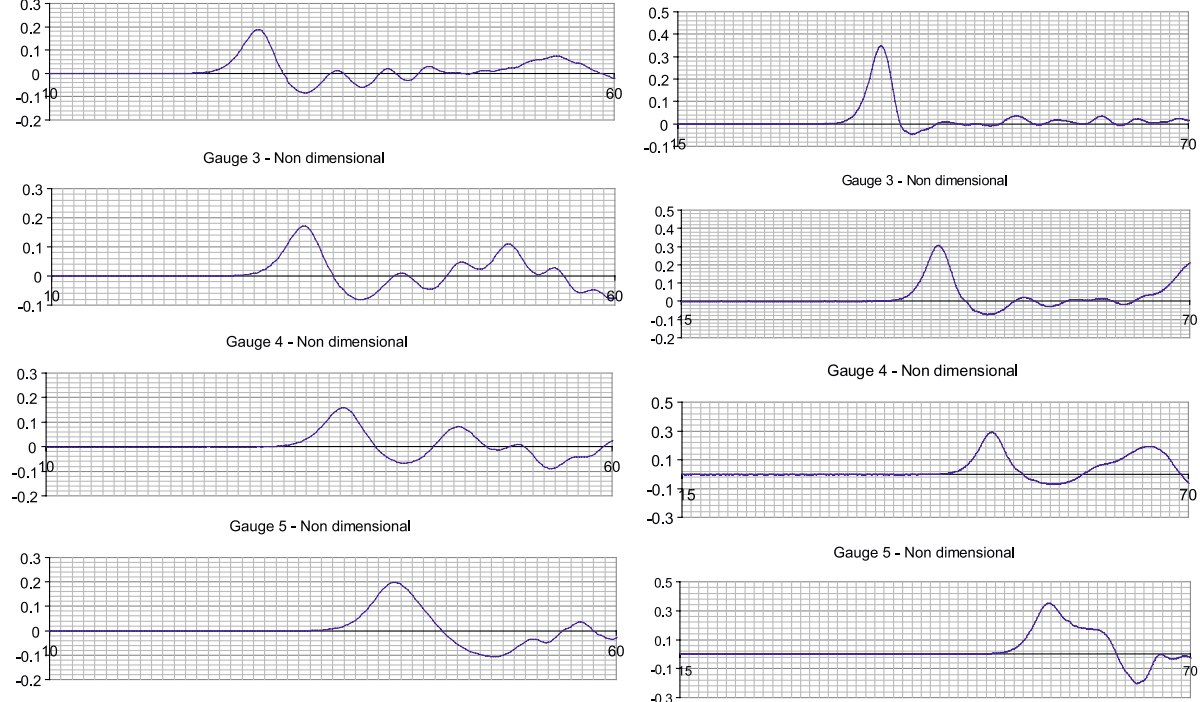

Gauge 4 - Non dimensional

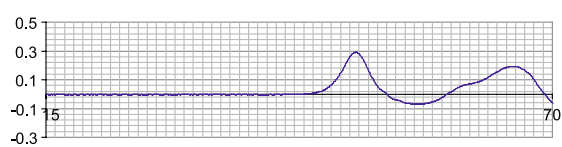

Gauge 5 - Non dimensional

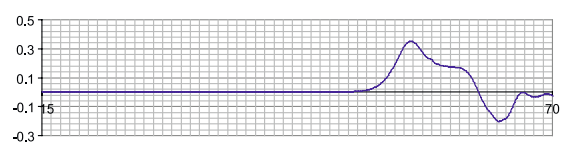

Fig. 7 Water level measurements $\left(h / h_{0} v s . t\left(g / h_{0}\right)^{1 / 2}\right)$ in gauges $\mathrm{n}^{\circ} 1$ to $\mathrm{n}^{\circ} 5(2 \mathrm{~m}, 4 \mathrm{~m}, 6 \mathrm{~m}, 8 \mathrm{~m}$ and $10 \mathrm{~m}$ upstream of the bank slope toe): a) E01; b) E16

the still water level in the reservoir, the slope and the initial position of the mass centre of the sliding blocks.

Concerning the generated wave characteristics, it has to be emphasized that they were based on values of the first wave amplitude obtained at the first gauge placed $2 \mathrm{~m}$ after the sliding bank. Having this in mind, values of $a_{c} / h_{0}$ are greater than 0.03 , all values of $a_{c} / L$ are greater than 0.006 and the Ursell number is always greater than 1 , which confirms the waves nonlinearity characteristics.

In most of the tests, the maximum wave amplitude was attained for the first wave. However, at gauge number 4 , placed $8 \mathrm{~m}$ from the bank, the amplitude of the second wave exceeded that of the leading wave in tests E10 and E11 (which correspond to higher bank slope, higher reservoir water levels and smaller volumes). This empathize the importance of the distance between the landslide and the bank.

The maximum was observed in E03 and E13 (which correspond to smaller bank slope, higher volumes and smaller reservoir depths), the minimum was observed in E04 (which corresponds to smaller bank slope, smaller volume and higher reservoir depth). The maximum negative wave amplitude was observed for E10 and E11 and the minimum for E16, where the wave shows characteristics similar to the solitary wave. The maximum positive wave amplitude has a strong dependence on both the mass (volume) of the sliding mass and the initial water level. To investigate the influence of the initial water depth, the tests E01, E04, E16, E19 and E20, where the initial water depths are different, were studied in particular. Figure 7 illustrates the water level measurements at the five gauges in tests E01 and E16, and 


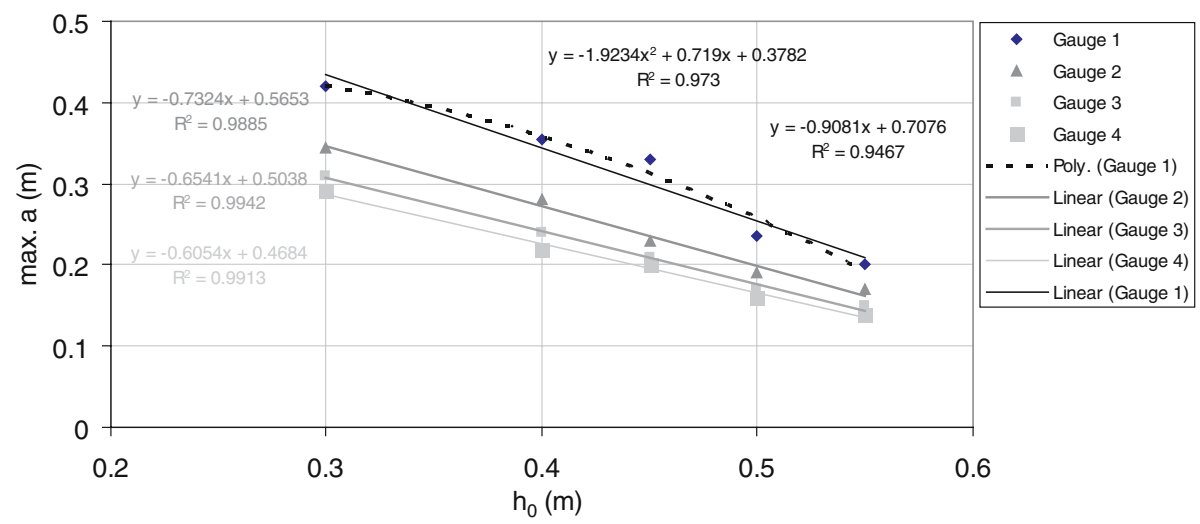

Fig. 8 Maximum amplitude variations on gauges 1 to 5 with the initial reservior water level: E01, E04, E16, E19 and E20

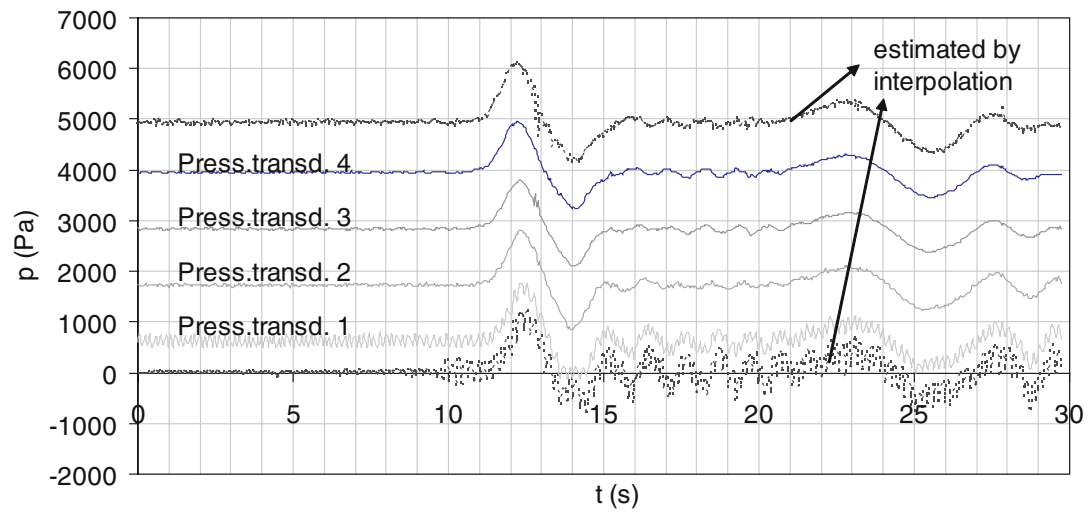

Fig. 9 Pressure values on the upstream face of the downstream bank: Test E01

Fig. 8 shows the maximum amplitude variations with the initial reservoir water level between $0.30 \mathrm{~m}$ and $0.55 \mathrm{~m}$ at gauges 1-4 (essays E01, E04, E16, E19 and E20).

Velocity, like the wave amplitude, is also very important for the risk prediction and hazard prevention, i.e. for efficient activation of emergency plans. For non linear waves, as those of this work, celerity is strongly dependent on the relative amplitude, $a_{c} / h_{0}$, wave length, $L$, and initial water level, $h_{0}$. Propagation velocity decreases with the amplitude and wave length. In the present study values in the range $0.9<a_{c 1} / \sqrt{g h_{0}}<1.2$ for the first wave and $0.6<a_{c 1} / \sqrt{g h_{0}}<1.0$ for the second one were obtained, which confirm this theory. According to the Boussinesq theory, the following expression for the solitary wave velocity is valid: $c_{c 1} / \sqrt{g h_{0}}=1+a_{c 1} /\left(2 h_{0}\right)$, where 1 refers to the first wave. This expression gives differences of less than $20 \%$ for all tests.

Hydrodynamic pressures on the downstream bank face were measured using pressure transducers. Instability was observed after a wave reflection upstream at the face of the downstream bank. Figure 9 illustrates pressure time history values at pressure transducers 1-4. At the bottom and at the top of the bank, the pressure values were estimated using Lagrange interpolation. Figure 10 illustrates the pressure diagrams at 4 instants, just before and after the maximum wave amplitude reached the bank and just before and after the minimum 
Fig. 10 Pressure diagrams on the upstream face of the downstream bank Test E01: a) just before and after the maximum wave amplitude reached the bank; b) just before and after the minimum wave amplitude reached the bank
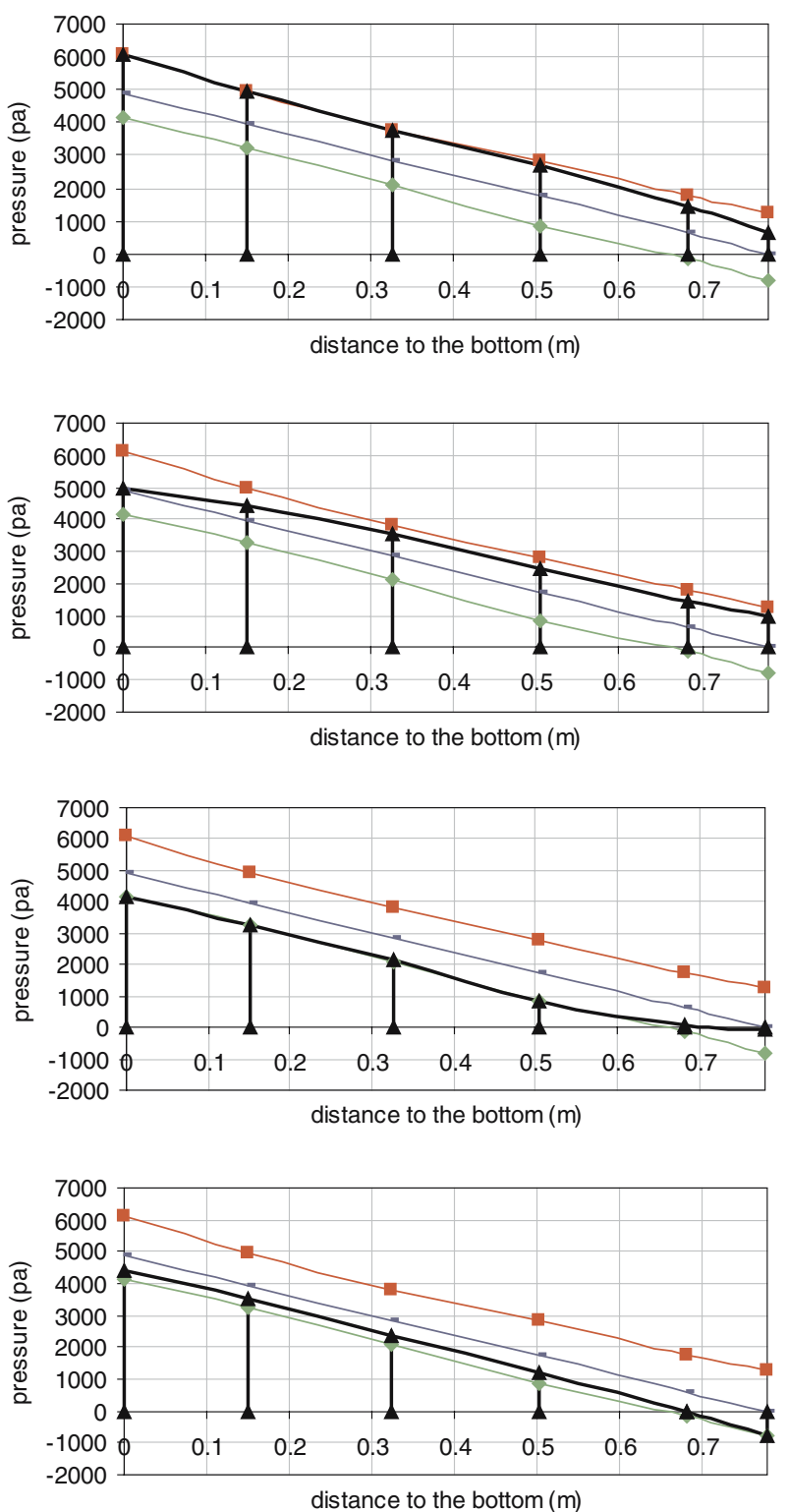

wave amplitude reached the bank, where a displacement of the hydrostatic diagram can be observed. Figure 11 illustrates the time history of the hydrodynamic forces exerted on the bank, and calculated using numerical integration (composite trapezoidal rule). Comparing Figs. 10, 11 and 7, it can be concluded that hydrodynamic forces show a time history variation similar to the pressure, but slightly different from the water level variation, possibly because the gauge signal is affected by reflexions on the upstream face of the bank.

For a better characterization, spectral analyses of the gauges signals were carried out. Figure 12 illustrates spectrums for gauges $n^{\circ} 1$ to $n^{\circ} 5(x=2 m ; 4 m ; 6 m ; 8 m$ and $10 m)$, 
Fig. 11 Hydrodynamic forces exerted on the upstream face of the downstream bank
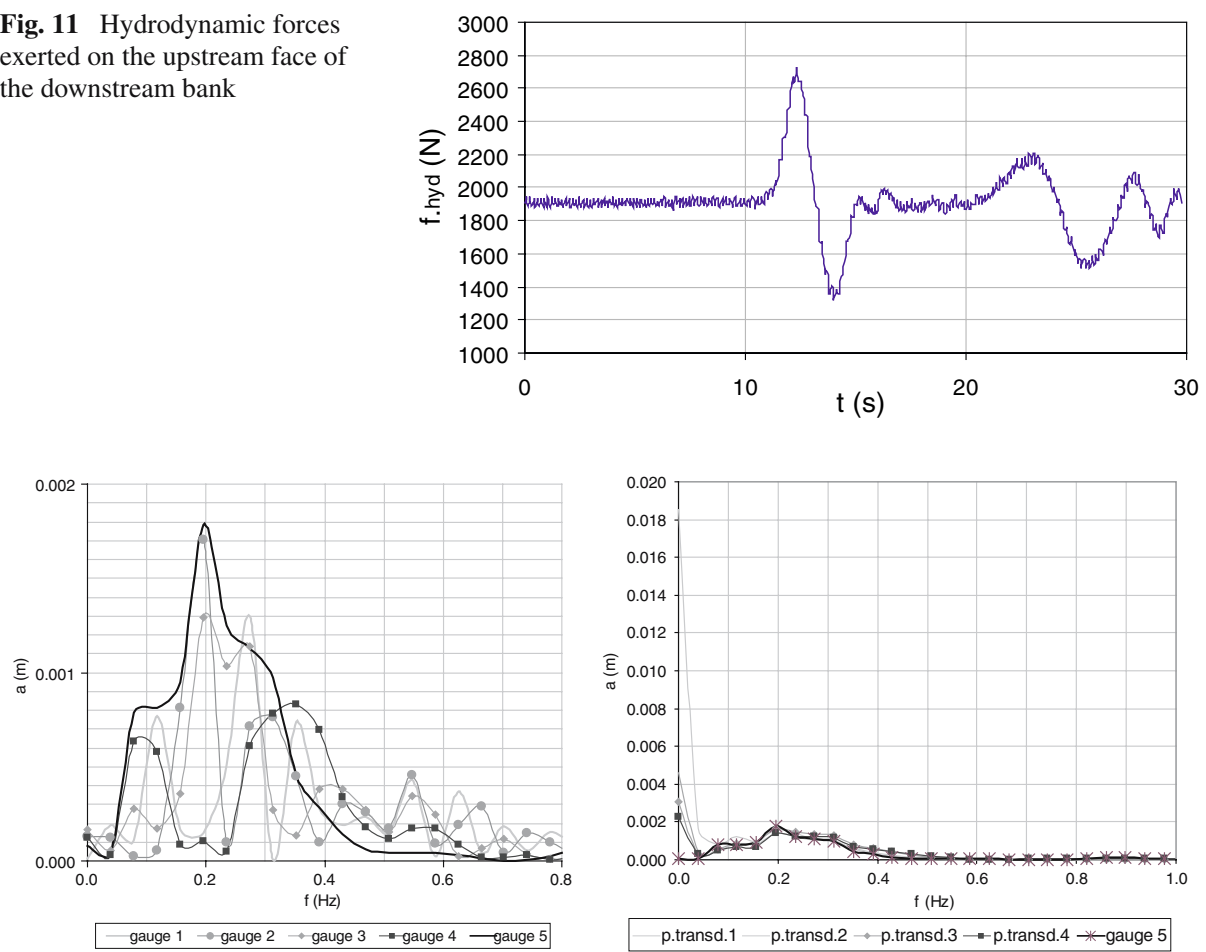

Fig. 12 Spectrums at test E01: gauges $n^{\circ} 1$ to $n^{\circ} 5$ and transducers $n^{\circ} 1$ to $n^{\circ} 4$

and from transducers $n^{\circ} 1$ to $n^{\circ} 4$ at E01. Analysing Fig. 12, the non linearity characteristic of the generated waves can be observed. It is also evident the increase of the non linearity close to and over the upstream face of the downstream bank.

\section{Conclusions}

Several tests of calcareous blocks sliding into reservoirs were conducted in order to analyse the subsequent waves generated and the hydrodynamic forces exerted on the upstream face of a bank placed downstream. Experimental data are presented, including slide velocity diagrams; water elevation time history at 5 gauges for different types of non-linear waves generated; hydrodynamic pressure at 4 transducers settled at the face of a bank placed downstream, pressure diagrams and hydrodynamic forces. Maximum amplitude variation of the initial reservoir water level and spectral analyses for the water and pressure variations are also presented. It is proposed a methodology based on the integrated study of slide bank-reservoir system and reservoir banks to understand the wave type and to obtain the hydrodynamic pressures exerted on the reservoir banks.

Different slide velocity diagrams: nearly linear, quasi-sinusoidal and parabolic; and different types of waves were generated depending on the relevant parameters: mass of the sliding blocks, still water level in the reservoir, slide velocity, sliding bank slope and initial mass centre position of the sliding blocks. The wave type could be predicted by a classification proposed by Noda [5], which is based on the Froude number for the slide velocity 
(obtained by an expression deduced from the energy balance) and dimensionless slide thickness. The maximum positive wave amplitude has a strong dependence on the mass (volume) of the sliding mass and on the initial water level, showing a quasi-linear variation.

More tests results are essential to support correlation and develop formulas able to predict the wave amplitude, velocity propagation, hydrodynamic pressures and forces. The transient analysis of the integrated system, slide bank, reservoir and structure bank is necessary for realistic analysis.

Acknowledgements The authors wish to acknowledge Portuguese Foundation for Science and Technology under the project POCTI/ECM/2688/2003, André Pestana for some experimental tests and calculations, and Mr. Joaquim Cordeiro, a technician of the LHRHA-DEC-FCTUC.

\section{References}

1. Carvalho RF, Antunes do Carmo JS (2006) Numerical and experimental modelling of the generation and propagation of waves caused by landslides into reservoirs and their effects on dams. In: Ferreira RML, Alves ECTL, Leal JGBA, Cardoso AH (eds) Proc River Flow 2006, vol 1. Lisbon, Portugal, pp $483-492$

2. Fritz HM (2002) PIV applied to landslide generated impulse waves. In: Adrian RJ et al (eds) Laser techniques for fluid mechanics. Springer, New York, pp 305-520

3. Fritz HM, Hager WH, Minor H-E (2004) Near field characteristics of landslide generated impulse waves. J Waterw Port Coastal Ocean Eng 130:287-300

4. Lynett P, Liu PLF (2005) A numerical study of the run-up generated by three-dimensional landslides. J Geophysical Research-Oceans 110(C3):Art. No. C03006 MAR 82005

5. Noda E (1970) Water waves generated by landslides. J Waterw Port Coastal Ocean Div Am Soc Civ Eng 96(4):835-855 